\title{
SOBRE LA EDUCACIÓN ESTÉTICA EN EL ÁMBITO FAMILIAR
}

\begin{abstract}
En 2004, la ONU conmemoró el Año Internacional de la Familia. Es nuestro interés tratar aquí un aspecto de la educación con frecuencia inescuchado (la educación estética) en un ámbito educativo primordial como es la familia, y a menudo también pasado por alto o dado por supuesto, centrándonos especialmente en la experiencia del cine como colaboradora de la educación estética. Resaltamos la relevancia del estilo familiar de vida, los hábitos elementales de higiene, vestimenta y alimentación, el uso de juguetes, la decoración y, especialmente, el trato en las relaciones humanas: gestos, usos del habla en las conversaciones, etc.

Todo ello colabora a poner en juego el cultivo de los sentidos externos: tacto, olfato, gusto, oído y vista, así como los internos: imaginación, memoria, experiencia de la vida. Y constituye una excelente preparación para la educación afectiva, moral, intelectual y social de los niños y las niñas.

Una concreción pedagógica de la educación estética en la familia la constituye el cine. Éste requiere especialmente el acompañamiento de padres y educadores durante los primeros años para extraer la virtualidad educativa que el cine encierra.

La estructura del texto responderá, por tanto, a tres apartados:

1. La educación estética en el desarrollo de la personalidad humana.

2. La familia como ámbito educativo en la esfera de lo estético.

3. Una concreción de la educación estética: el cine.
\end{abstract}

ABSTRACT. In 2004 the United Nations was conmemorating the tenth anniversary of the International Year of the Family. On this occasion, it was fitting to consider an aspect of education which can be developed in the family, but hardly receives much attention in that context. We refer to aesthetic education. The scope of this education is diverse: family life style, personal hygiene, manner of dressing, care in the use of material things, decorum. The latter includes the gestures and manner of speaking as one interacts with others.

Aesthetic education involves the proper cultivation of the external senses - touch, smell, taste, hearing and sight - and the internal senses such as the imagination, memory and life experience. The achievements in aesthetic education redound to the other spheres of education: emotional, moral, intellectual and social.

By way of an example, the use of movies as a means to promote aesthetic education in the family is explained. To draw out the maximum educational potential of this medium, the active involvement of parents especially during the child's early developmental stage is indispensable.

The paper is divided into three parts: 
1. The role of aesthetic education in the development of the human personality.

2. The family as the setting for aesthetic education.

3. Movies as a medium for aesthetic education.

KEY WORDS: Aesthetic Education, Civic Education, Early Childhood Education, Family Education, Film Appreciation

\section{INTRODUCCIÓN}

Se constata en la literatura educativa de los últimos años cada vez una mayor conciencia - al menos en teoría - de la necesidad de atender más y mejor a este aspecto de la educación que es la educación estética (Delhors, 1996; Naval y Altarejos, 2000; Eisner, 2002), aunque en ocasiones haya podido quedar en bienintencionadas declaraciones de principios.

'Qué aporta la educación estética en el conjunto de la formación humana'. Lógicamente las diferencias de edad son un elemento clave a tener en cuenta al hablar de la educación estética. Aquí nos interesan las edades más tempranas al centrarnos posteriormente en el ámbito familiar, pero es un telón de fondo irrenunciable en toda etapa educativa, lo que es lo mismo que decir, en toda la vida humana.

\section{LA EDUCACIÓN ESTÉTICA EN EL DESARROLLO DE LA PERSONALIDAD HUMANA}

Toda cuestión relativa a la sensibilidad está enraizada necesariamente en la noción de corporalidad (Urpí, 2000, p. 138). La educación estética incide en la sensibilidad, es decir, en la formación de los sentidos externos e internos (Naval y Altarejos, 2000, pp. 218-222). De modo coordinado, integrado, la educación afectiva incide o actúa en el ámbito de los deseos e impulsos, y para tener el cuadro completo y descubrir el sentido de la educación estética y afectiva, convendría que apuntáramos también a la educación intelectual y la educación moral, propiamente dicha, sin olvidar la educación social o cívica. Estas distinciones analíticas pueden ser engañosas porque no son reales. La persona es una y cualquier actuación suya afecta a toda la persona, al igual que cualquier intervención educativa a un nivel repercute en los demás y encuentra su sentido en la integración de los distintos ámbitos. 
Es una expresión usual cuando se habla de la educación estética, hablar de "afinar o educar el gusto", significando en primera instancia reconocer la belleza. Ya se ve que no se trata sólo de cualidades cognoscitivas, sino de tener el gusto educado, de haber cultivado y desarrollado esa capacidad. Esta educación del gusto "se logra a través de un proceso en el que se cultiven las inclinaciones que hay por naturaleza en la persona humana" (Retegui, 1999, p. 62). Las vías para suscitar este tipo de formación son variadas, pero acaso el camino más eficaz para conseguirlo no es otro que "la cercanía, el contacto, la connaturalidad con la belleza auténtica que se encuentra en personas, situaciones, cosas" (Ibíd.).

No es nada nuevo afirmar que la experiencia estética es un elemento fundamental en la formación de las personas, pero hay que tener en cuenta que las experiencias estéticas que más influyen en ocasiones no son las que suponen simplemente contemplar obras de arte, sino las que nos ponen en contacto con la experiencia de la belleza en las situaciones humanas.

Así se entiende que educar el gusto no es sólo, ni principalmente, aunque colabore a ello, ir a ver museos, adquirir conocimientos de arte o recitar poesía, sino fundamentalmente participar intensamente en "situaciones humanas adecuadas de relación con otros al más alto nivel": conversaciones, discursos, contactos con maestros marcados por una afinidad con la verdad, coherentes en su decir y obrar, etc. Este papel lo cubren también las historias en la vida de los pueblos (MacIntyre, 1987, p. 155).

\section{Sentidos externos y sentidos internos}

El problema, en parte, ha sido en años pasados, haber elaborado una educación estética excesivamente espiritualista, despegada de la formación de la sensibilidad, como si fuera la coronación o el tejado del edificio, cuando en realidad también está en la base. Podemos decir que no cabría una experiencia estética que no se realizara en y desde los sentidos.

De este modo, parece que habitualmente la vista y el oído son los sentidos que más se privilegian en el ámbito de la educación estética los sentidos menos materiales, podríamos decir - pero se puede afirmar sin complejos de ningún tipo que todos ellos tienen su papel, e incluso es a los sentidos más materiales - gusto, olfato y tacto - a los que corresponde el comienzo o iniciación de la sensibilidad. La ayuda 
educativa aquí es meramente dispositiva y puede ejercitarse paso a paso, como iremos viendo.

Así el primer sentido que se pone en juego es el tacto, después el olfato y el gusto, seguidos del oído y la vista. Aquí cabría mencionar la importancia que tienen, en cuanto inciden en los sentidos externos, de cara a la formación de la sensibilidad en la infancia - y de algún modo a lo largo de toda la vida -: la vestimenta, la higiene corporal, la comida, las conversaciones y demás sonidos, el orden y decoración del hogar, los juguetes y objetos con los que tiene contacto, etc. También conviene atender a los gestos y movimientos.

Un paso más sería - ya en el ámbito de la sensibilidad interna -: sentir que sentimos (vemos, oímos, gustamos, etc.), imaginar, recordar y proyectar esas imágenes o recuerdos en el futuro particular. La actuación educativa puede incidir en cada aspecto. Merece especial mención la educación de la imaginación y el papel que en ella tiene por ejemplo la enseñanza del dibujo. En realidad - dice Yepes (1996, p. 39) - "la creatividad humana es un uso inteligente de la imaginación".

Junto a la educación de la imaginación, la educación de la memoria es parte importante de la educación estética, que se ocupa de los recuerdos sensibles, es decir particulares y concretos, cuyo referente es el pasado. Se apoya en las demás capacidades sensibles para su formación y desarrollo. Ha sido oscilante el tratamiento educativo de este aspecto de la realidad humana, restándole valor e importancia en épocas de mayor influencia racionalista, tratando de evitar la sobrevaloración que tuvo en otros momentos. No en vano apuntaban los griegos al aprendizaje y recitación de poesías como rico y valioso ejercicio educativo.

Además de cultivar la memoria, que se refiere al pasado, conviene en este nivel de formación de la sensibilidad - aprender a proyectar en el futuro: a "estimar", o relacionar la realidad exterior con la propia realidad (en el ámbito de sensibilidad interna) (Vicente and Choza, 1992, p. 190), de donde se origina la experiencia de la vida. La narrativa juega - educativamente hablando - un papel clave en este ámbito: son vidas en acción, sean leídas - cuentos, literatura, etc. - o vistas y escuchadas - cine, teatro, etc. - las que contemplamos. Vidas que podrían ser las nuestras, y que despiertan en nosotros unos sentimientos de alegría, pena, compasión, rechazo, aprobación, identificación, etc. y que colaboran a ese aprendizaje tan importante y básico 
que consiste en aprender a alegrarse con lo bueno y a entristecerse con lo inadecuado, dañino. Así enlazaríamos de modo natural la educación estética con la educación afectiva, que incide en el ámbito de los deseos y los impulsos.

\section{Vergüenza, pudor, ridículo, compostura, elegancia y belleza}

Después de esta visión más analítica de la educación estética y pensando no sólo en los niños sino en cualquier edad de la vida humana, podemos decir que la educación estética puede verse en relación con algunos sentimientos como la vergüenza, el pudor, el sentimiento del ridículo y con algunos rasgos de carácter como la compostura y la elegancia.

Teniendo en cuenta que "la presencia de lo bello y de lo feo en nosotros mismos es una parte decisiva de nuestra dignidad" (Yepes, 1997, p. 71), son muy significativas preguntas tales como: 'qué aspecto tengo'. 'Cómo me ven los demás'. 'Me ven tan horrible o tan feliz como me siento'. 'Qué piensan de mí'. La vergüenza, el pudor, la compostura y la elegancia son así actitudes que preservan o protegen nuestra dignidad.

En palabras de Scheff, "la vergüenza es la emoción social, al surgir regulando las propias acciones al mirarse uno mismo desde el punto de vista de los otros" (Scheff, 1990, p. 80). Lógicamente la vergüenza, como todo sentimiento, requiere orientación adecuada, para avergonzarse con lo que es debido, como es debido, en la medida que es adecuado y evitar así sentimientos de inferioridad o pérdidas de autoestima que en último término quitan libertad interior a la persona y paralizan la acción.

El ridículo sería un subcapítulo dentro de la familia de sentimientos que incluye la vergüenza, cuando nos fijamos más en la proyección de la propia imagen en los demás. Aristóteles apunta a lo ridículo, como lo feo o innoble sin dolor (Aristóteles, Poética, 1449a 32-34) aludiendo a la falta de trascendencia en los hechos que lo producen.

Estrechamente relacionado con la vergüenza está otro sentimiento: el pudor: "la inclinación a poner la intimidad a cubierto de miradas extrañas" (Yepes, 1997, p. 73) o también podría ser definido como amor a la propia intimidad. Uno siente vergüenza porque se "siente visto", sin quererlo, en su intimidad; por eso surge la reacción de ocultarla, protegerla. Si muestra su intimidad es por un acto de libertad, no por una violación de ella. 
El pudor afecta también al cuerpo porque forman parte de la intimidad y de la dignidad, el vestido, los gestos, los movimientos más variados (comer, el aseo, etc.). Del mismo modo se aplica a la vivienda, al hogar y al modo de expresarnos - lenguaje - tanto oralmente como por escrito. El pudor es como una invitación a tratar de ver, más allá de las manifestaciones que se nos ofrecen, a la persona que está detrás.

Cuando se ha perdido la capacidad de percibir los límites de lo vergonzoso - el sentido de lo decente que protege los valores comunes de una sociedad, implica una pérdida del valor de lo íntimo, un aumento de la superficialidad. Urge entonces recuperar el sentido de lo digno, de lo decente.

Pero dando un paso más allá de la vergüenza y el pudor, 'cómo surge lo bello en la persona: en su figura, actos, movimientos' "Guardar o perder la compostura" sería el primer peldaño, en cuanto la compostura modera y templa las acciones externas. Acaso hoy alguno la definiría como "buenas maneras", cortesía o "buena educación" en el sentido más elemental y simplista de la expresión, reducida a usos sociales. Mantener la compostura supone esfuerzo, tiempo y cuidado.

Además de no desentonar cabe desarrollar el buen gusto y alcanzar una cierta elegancia que pone a la persona por encima del anonimato. La belleza se hace así presente en la persona y es armonía y proporción de las partes dentro del todo. Pero la belleza no es sólo física, sino también moral: dimensión moral de la elegancia. Así quien no es dueño de sí mismo, quien no se controla, quien no vive el respeto, difícilmente será elegante en un sentido radical, aunque lleve ropa de marca, tenga un asesor de imagen de primera, o vaya al más sofisticado salón de belleza.

Ahora bien, el adorno, el vestido, el gesto, la proporción, juegan un papel importante en la elegancia y esto se aprende, aunque haya modos de ser mejor dispuestos que otros. Aprender a ser elegante es negarse a la uniformidad, al anonimato; atreverse a expresar la propia personalidad, dar cauce a la creatividad. También es aprender a celebrar aquellos acontecimientos que se lo merecen y son dignos de ese gesto o adorno en la persona. En las fiestas, las personas se transforman; parecen distintas, siendo ellas mismas. Con ayuda o por propio arte tratan de distinguirse, con más o menos acierto. Se expresa la alegría por medio del adorno, entre otras cosas.

Entonces juega un papel importante otra característica de la elegancia: la naturalidad en la expresión: ser uno mismo, mostrarse como 
uno es, que es algo distinto a la abrupta espontaneidad descontrolada, o a la mera imitación de modelos vistos en otros. El verdadero estilo excluye el cliché. La misión del estilo propio no es, en fin, la de brillar sino la de dejar aparecer (Sertillanges, 2003, pp. 162-166).

\section{LA FAMILIA COMO ÁMBITO EDUCATIVO EN LA ESFERA DE LO ESTÉTICO}

\section{Desde la cuna}

Desde los primeros meses de vida los bebés empiezan a forjar una sensibilidad externa e interna, un "conocimiento somático" (Eisner, 2002, p. 19). Van discriminando el gusto por las cosas, primero desde el dolor o placer que les producen, y poco a poco van aprendiendo a distinguir más matices entre lo que les parece bueno y gustoso y lo que les parece desagradable y malo. Todo esto constata la importancia que tienen esos primeros años para la educación estética y, por consiguiente, también la familia y su entorno.

Pero existe una primera condición para que la familia sea favorable a una educación estética, que también se puede observar en otros aspectos de la educación en general. Se trata de la necesidad de que el ambiente familiar sea suficientemente armónico y rico en comunicación. "Es posible empezar a hablar de una acción pedagógica familiar continuada sobre todo cuando las dificultades cotidianas están contrarrestadas por un buen clima de cohesión y comunicación" (Puig Rovira y Trilla, 1996, p. 151). Supuesta esta primera condición, la familia constituye un magnífico lugar para iniciar la educación estética.

\section{En busca de objetividad y de racionalidad}

La historia del pensamiento, e incluso el saber popular, han contrapuesto dos cualidades de la persona humana: el sentido común (entendido como sensatez) y la sensibilidad. Como si se tratara de dos cualidades incompatibles en una misma personalidad, se describe a alguien - muchas veces a figuras artísticas - por su habitual falta de sensatez pero con una rica y fina sensibilidad; mientras que otra persona será muy sensata pero poco sensible. Esto se debe sobre todo a que se ha entendido habitualmente el sentido común como una capacidad humana perteneciente exclusivamente al orden de lo 
racional, mientras que la sensibilidad parece haber estado más ligada a instancias irracionales.

Sin embargo, como afirma el filósofo Nelson Goodman: "la experiencia estética (...) abarca hacer discriminaciones delicadas y discernir sutiles relaciones, identificar sistemas simbólicos y caracteres dentro de esos sistemas, así como qué denotan y ejemplifican esos caracteres, interpretar obras y reorganizar el mundo en términos de obras y las obras en términos del mundo" (Eisner, 2002, p. 37). El nivel de complejidad va en aumento a medida que se da una búsqueda mayor de la artisticidad en el obrar, entendida como "una forma de práctica informada por la imaginación que emplea la técnica para seleccionar y organizar cualidades expresivas para alcanzar fines que son estéticamente satisfactorios" (Eisner, 2002, p. 49). Toda práctica artística mejora cuando el sujeto aprende a reflexionar sobre los propios resultados, asistida por la información crítica de los demás, que en el medio familiar suele ser muy común por parte de los padres, hermanos y otros miembros cercanos.

Además, desde una visión antropológica y pedagógica se entiende que la sensibilidad es precisamente una primera referencia para la formación del juicio racional posterior (Choza and Arregui, 1992), de modo que más que contrarios, serían complementarios. Sin embargo, también cabe decir que la experiencia estética como experiencia que integra lo sensible emotivo y lo cognoscitivo tiene además un valor intrínseco, un valor en sí misma, al que la educación no debería renunciar (Labrada, 2002). Y es en la familia donde la experiencia estética encuentra su primera ordenación educativa, de un modo informal.

Las estrechas relaciones que se viven en el hogar familiar son el escenario idóneo para vivir, al menos, dos de las cualidades intrínsecas a la experiencia estética. La vivencia en la familia de la gratuidad de las relaciones, que van más allá del cuidado y la necesidad, y la vivencia de la satisfacción o goce que se experimenta en ellas, suponen un primer aprendizaje hacia lo propio de la experiencia estética, que se define en parte como la vivencia de un goce desinteresado. Hay otro tipo de vivencias cercanas a la estética que también contienen estas dos cualidades, como el juego, por ejemplo. Pero una experiencia estética incluye un componente contemplativo. En la contemplación estética de la belleza se da la unión del conocimiento y del afecto en un acto de aceptación de la realidad tal cual es, sin pretensión alguna de modificarla ni manipularla, quedando su existencia justificada por sí misma (Yepes, 1996, p. 152). Esta actitud contemplativa, como ingrediente 
indispensable en toda experiencia estética, también puede ser fomentada en la familia, donde las relaciones entre las personas que la integran pasan por la aceptación de los demás por quienes son y no sólo por lo que tienen o dan (Alvira, 1998). También aquí se vive la experiencia del encuentro con el otro como una superación de la subjetividad personal, como el encuentro de aquella objetividad buscada.

\section{Pedagogía familiar}

Dos principios fundamentales en la educación son el principio de individualidad y el de sociabilidad: toda persona puede desarrollarse como individuo único e irrepetible, distinto de todos los demás, a la vez que puede hacerlo en comunidad con los demás, es decir, desarrollando integralmente su sociabilidad. La integración de ambos principios da lugar a un tercero que culmina, en cierto modo, el proceso educativo: el principio de autonomía (González Simancas, 1992, p. 91). La adquisición de la autonomía personal es, por tanto, un objetivo principal en todo proceso educativo, también en aquel que tiene lugar en el seno familiar.

El escenario familiar ofrece considerables ventajas respecto a la consideración de estos tres principios educativos en la esfera de lo estético.

En cuanto al principio de individualidad, las relaciones entre los miembros de una familia se viven de manera íntima e intensamente personalizada desde el mismo momento en que unos padres ponen el nombre a su hija o hijo para distinguirle como único ante los demás. El trato personal entre los miembros de una familia se caracteriza por tener un alto grado de intimidad e individualización. Cada miembro es percibido por los demás como distinto y único, reconocido como absoluto (Alvira, 1998). En la esfera de lo estético, el desarrollo de esta unicidad es especialmente imprescindible. La impronta de subjetividad que siempre destaca en las acciones estéticas proviene sin duda de una individualidad desarrollada, del carácter único o estilo personal expresado en el obrar o en la obra como manifestaciones de la personalidad. La originalidad del arte proviene de una personalidad individual.

En cuanto al principio de sociabilidad, el seno familiar es el ámbito relacional en el que el niño o niña se estrena desde que nace, con unas relaciones basadas en el afecto y el conocimiento íntimo. La 
educación estética, tan ligada a la educación emocional, encuentra en este ambiente de relaciones un escenario fértil en posibilidades educativas.

El aprendizaje de símbolos cargados de connotaciones significativas no sólo a nivel cognitivo sino también a nivel emocional y afectivo educa la capacidad de percepción sensible de la realidad, y refina su consecuente interpretación. Y por eso, además, en este ámbito relacional aparece la expresión sensible de la propia personalidad, se fragua el estilo propio y se comparte la intimidad personal en las diferentes manifestaciones expresivas y de comunicación con los otros familiares (actuaciones todas necesarias para la educación estética).

Cualquier planteamiento pedagógico sobre lo estético incluye no sólo el aspecto perceptivo de la realidad sino también educar el aspecto expresivo del yo (Pérez Alonso-Geta, 1998, pp. 758-769). El movimiento se da en ambas direcciones de dentro a fuera y de fuera a dentro: por un lado, es preciso educar la receptividad sensible del yo frente al mundo, frente al no-yo, a lo externo; por el otro, es necesario educar también la expresividad creativa de la interioridad que se abre en la comunicación con los demás, con el exterior.

En este punto se ve con claridad la necesaria complementariedad educativa que existe entre individuo y sociedad, contemplada por aquella idea de educación integral mencionada en las primeras páginas. La apertura a los demás de la propia subjetividad personal completa de alguna manera (sin que se acabe, sino quedando aquélla trascendida) el desarrollo mismo de la individualidad (Naval y Altarejos, 2000, pp. 176-184). Esto nos llevará directamente al tercer punto: la autonomía.

El principio de autonomía, que se desprende de los dos anteriores, sólo es posible cuando un individuo se desarrolla como tal dentro de un grupo social, permitiéndole alcanzar pleno dominio de sí mismo. El papel educador de los padres en este aspecto de la autonomía requiere importantes decisiones tácticas, puesto que se trata de ir evolucionando en su papel de facilitador de la madurez del niño: si la intervención de los padres es excesiva o se adelanta a la situación de aprendizaje estará fomentando un hijo dependiente, si en cambio descuida su apoyo o lo ejerce demasiado tarde, pone en peligro la autoestima necesaria del niño para convertirse también en un ser autónomo (Eisner, 2002, p. 73). 
La atmósfera familiar de respeto hacia su persona en que un niño o una niña crecen, propicia el desarrollo de la autonomía personal mediante el ejercicio progresivo de la libertad. Y todas esas experiencias de libertad personal que se van viviendo evolutivamente en el seno familiar son muy valiosas a la hora de desarrollar una creatividad personal, un estilo propio en el modo de hacer las cosas, una personalidad original.

El desarrollo de la autonomía queda enmarcado dentro de unas formas concretas que perfilan y llenan de carácter y vida el obrar de cada persona. Pero tal como se apuntaba al principio, se trata de la educación del gusto estético no sólo a través del arte sino sobre todo a través de aspectos cotidianos de la vida humana tales como la apreciación y el cuidado del medio, el cuidado personal (la higiene, la vestimenta), las relaciones con los demás (el habla, los gestos, etc.).

\section{UNA CONCRECIÓN ESTÉTICA: EL CINE}

El cine es un fenómeno con una especial importancia actualmente en la vida social y familiar, moviliza a un gran número de personas. Aunque ver la televisión, escuchar la radio o leer periódicos son actividades que están por encima según datos de opinión sobre consumo cultural, en España el cine supera en frecuencia de asistencia a bibliotecas, museos, teatros, salas de conciertos (CIS, 1999).

Por otro lado, ver cine es una actividad cultural que se desarrolla en muchas ocasiones dentro del hogar familiar, cuando se alquila una película de vídeo o cuando se ve en televisión. También se da como una actividad especial de la familia que programa una salida conjunta a una sala cinematográfica, sobre todo, en los años infantiles en que todavía los hijos acuden acompañados.

Sin entrar aquí en el manido tema de la comercialización del arte, merece alguna mención el problema de fondo que existe al hablar de educación estética en relación con el cine. Es un hecho que no todas las películas que se estrenan pueden clasificarse dentro del denominado "séptimo arte", sino que muchas provienen más bien de una concepción del cine como puro entretenimiento. Por eso, la consideración de la posibilidad educativa que encierra el cine como arte no se puede hacer extensible aquí a aquellas películas realizadas y pensadas desde un principio con el único fin de obtener el mayor éxito de taquilla. En realidad, el principal objetivo en materia de educación estética respecto al cine consiste precisamente en educar el gusto por 
el buen cine, en poder distinguir la calidad artística de una película y aprender a elegirlas; o lo que es lo mismo, en aprender a disfrutar de las películas de calidad y a rechazar dis-gustadamente (en el sentido más literal del término) las que no la tienen.

Son muchas las virtualidades educativas que encierra el cine como arte. El cine nos enseña distintos modos de mirar y percibir la realidad. Las miradas que una película nos descubre como espectadores, las vertemos después sobre nuestros paisajes y rostros cotidianos, descubriendo en ellos nuevos significados. Además, las emociones que sentimos al identificarnos con los hechos de la película y los pensamientos que vamos anticipando al hilo narrativo, no son otra cosa que continuos ensayos asegurados - casi aprendizajes por ensayo y error de la afectividad y el conocimiento -, que la ficción nos permite sin peligro de correr el riesgo que la realidad nos impondría. Podemos aventurarnos como el protagonista ante una situación de peligro porque no corremos ningún riesgo real (Urpí, 2000, p. 265; Grimaldi, 1994).

\section{Algunas orientaciones pedagógicas}

\section{Clasificación por edades}

La cuestión sobre la adecuación de la edad de los espectadores es ineludible, y no sólo desde el punto de vista del contenido, como es habitual argumentar, sino también desde el punto de vista cinematográfico (en el sentido más literal de kinematographía: "imágenes en movimiento"). 'A qué edad se debería empezar a ver cine', 'qué duración debería tener una película para los más pequeños'

Desde el punto de vista pedagógico, es sabido que cada momento evolutivo en el niño requiere una estimulación adecuada. Si aplicamos este criterio en la experiencia del cine, parecerá conveniente evitar la tan habitual sobrestimulación de los niños. Por ejemplo, sería absurdo pretender que un niño que todavía no habla ni entiende una mínima conversación, sea capaz de ver una película en la que durante una hora se desarrolla una historia narrativa con diálogos abundantes entre los personajes, por muy infantiles que sean los dibujos que representan esos personajes. El niño es todavía incapaz de captar la información que ofrecen las secuencias narrativas. Se podría argumentar, sin embargo, que el niño selecciona los estímulos que le interesan y que el resto de información no tiene por qué dañar su desarrollo; sin embargo, esa sobrestimulación causa confusión en el niño, del mismo modo que lo haría hablarle con un lenguaje de adultos. Conviene empezar con películas de corta duración y poca complejidad 
narrativa. Existen cortometrajes infantiles que apenas cuentan un solo hecho con sus consecuencias más inmediatas, siendo este tipo de episodios más adecuados y valiosos para los más pequeños.

\section{El contexto}

En la sala de estar familiar el espectador infantil se acostumbra a ver cine en condiciones llenas de inconvenientes: cortes publicitarios, ruidos ambientales, interrupciones telefónicas, conversaciones paralelas, actividades simultáneas como comer, hacer tareas escolares, jugar, etc. Y cuando el ambiente impide la concentración y la disposición necesarias, los valores educativos del cine disminuyen; sobre todo, los estéticos.

La sola decisión de acudir hasta una sala de cine, elegir entre las opciones de la cartelera o pagar una entrada, supone una mayor implicación personal por parte del espectador que, además, se acomoda después en una butaca individual, a oscuras y sin las interrupciones típicas del hogar familiar; de modo que la niña o el niño aprende desde el principio que se trata de un espacio y un tiempo acotados específicamente para una actividad, a la vez que aprende a predisponer su capacidad de percepción sensible y de reflexión ante un objeto elegido particularmente.

\section{El papel del acompañante-educador}

El elevado nivel de implicación del niño-espectador con la película debido a la estrecha relación que se establece en la sala debería contrarrestarse a través de conversaciones posteriores que ayuden a objetivar la experiencia. Además, las nuevas tecnologías aplicadas al cine (sobre todo el de animación) aumentan el impacto sensible sobre el espectador. Aprender a descifrar ese impacto, descubrir su alcance, supone un objetivo educativo primordial.

Por lo general, los espectadores infantiles suelen preguntar muchas cosas al salir del cine, algunas que no han entendido bien o con las que no estaban de acuerdo. Es conveniente que el adulto no eluda la pregunta y exprese su parecer. Razonar en voz alta la propia experiencia para comunicarla a los demás es una excelente forma de enseñar a ser un espectador objetivo y crítico.

También es importante el momento previo a ver la película: elegir de manera conjunta la película, considerando su mayor interés; informarse de qué trata, de su calidad artística, de su duración; indagar si hay escenas especialmente violentas o agresivas para el niño; considerar la referencia a otras películas relacionadas. A pesar 
de todo, es posible que una vez en el cine la elección sea un fracaso, pero aun así es una oportunidad educativa.

En definitiva, para disfrutar de la experiencia estética del cine es fundamental que la compañía de padres y adultos se prolongue más allá de la sala, en conversaciones y comentarios que permitan comunicarse mútuamente la experiencia vivida. Naturalmente, esto que hemos ido tratando con una de las concreciones de la educación estética como es el cine, puede extenderse a otras situaciones educativas, pero sería ya un asunto que nos ocuparía otro artículo.

\section{REFERENCES}

Altarejos, F. \& Naval, C. (2004). Filosofía de la educación, 2nd edn. Pamplona: EUNSA .

Alvira, R. (1998). El lugar al que se vuelve: reflexiones sobre la familia. Pamplona: EUNSA.

CIS (1999). Consumo cultural. Estudio CIS 2324. Boletín 22, octubre-diciembre 1999.

Choza, J. (Ed.) (2003). Sentimientos y comportamiento. Murcia: Universidad Católica San Antonio .

Choza, J. \& Montes, M.J. (2001). La antropología en el cine: construcción y reconstrucción de lo humano. Madrid: Ediciones Laberinto.

Delhors, J. (1996). La educación encierra un tesoro. Madrid: Ediciones UNESCOSantillana.

Eisner, E.W. (2002). The arts and the creation of mind. New Haven: Yale University Press.

Frossard, A. (1994). Preguntas sobre el hombre. Madrid: Rialp.

García Costoya, A. (2003). El sentimiento del ridículo y su poder de configuración social. In J. Choza (Ed), Sentimientos y comportamiento (pp. 201-228). Murcia: Universidad Católica San Antonio.

Gennari, M. (1997). La educación estética: arte y literatura. Barcelona: Paidós.

Grimaldi, N. (1994). El aprendizaje de la vida a través del cine y la literatura. Nuestro Tiempo, diciembre 1994, pp. 116-125.

González-Simancas, J.L. (1992). Educación, libertad y compromiso. Pamplona: EUNSA.

Innerarity, D. (2003). La vanidad y el orden social. In J. Choza (Ed), Sentimientos y comportamiento (pp. 187-200). Murcia: Universidad Católica San Antonio.

Johnson, M. (1987). The body in the mind: The bodily basis of meaning, imagination and reason. Chicago: University of Chicago Press.

Labrada, M.A. (1998). Estética. EUNSA: Pamplona.

MacIntyre, A. (1987). Tras la virtud. Barcelona: Crítica.

Naval, C. (1993). Educación, retórica y poética. Pamplona: EUNSA.

Pérez Alonso-Geta, P.M. (1998). Educación estética. In F. Altarejos et al. (Ed), Filosofía de la educación hoy (pp. 758-769). Madrid: Dykinson. 
Peters, R.S. (1969). El concepto de educación. Buenos Aires: Paidós.

Puig Rovira, J.M. \& Trilla, J. (1996). Pedagogía del ocio. Barcelona: Laertes.

Ruiz Retegui, A. (1999). Pulchrum. Madrid: Rialp.

Scheff, T.J. (1990). Microsociology. Discourse, emotion and social structure. Chicago: University of Chicago Press.

Sertillanges, A.-D. (2003). La vida intelectual. Madrid: Ediciones Encuentro.

Urpí, C. (2000). La virtualidad educativa del cine. Pamplona: EUNSA.

Vicente, J. \& Choza, J. (1992). Filosofía del hombre: una antropología de la intimidad. Madrid: Rialp.

Yepes, R. (1997). La persona y su intimidad, Cuadernos de Anuario Filosófico, 48. Pamplona: Universidad de Navarra.

Yepes, R. (1996). Fundamentos de antropología. Un ideal de la excelencia humana. Pamplona: EUNSA.

Department of Education

University of Navarra

31080 Pamplona

Spain

E-mail:cnaval@unav.es 